\title{
Removal of heavy metals from synthetic solution by electrocoagulation
}

\author{
Mohamed Ilou, Fatima Abida, Zineb Hatim and Abdelmoula Kheribech* \\ Laboratory of the Water and the Environment, Team of Biomaterials and Electrochemistry, Faculty of Science, \\ 24040 El Jadida-Morocco
}

\begin{abstract}
The objective of this work concerns the optimization of the operating conditions for the removal of heavy metals from synthetic solution by Electrocoagulation (EC). To reach this purpose, we prepared a synthetic wastewater containing certain heavy metals $(\mathrm{Ni}, \mathrm{Cu}, \mathrm{Zn}, \mathrm{Fe}$ and $\mathrm{Pb}$ ) to study the influence of various parameters (conductivity, $\mathrm{pH}$, time of electrolysis, current density and the initial concentration of the metal) on the rate of removal of these metals. The results show that this rate of removal can reach $99.9 \%$ in the following optimal conditions: $\mathrm{pH}$ included between 6 and 8 and a density of the current of $1 \sim 1.5 \mathrm{~A} / \mathrm{dm}^{2}$. This study shows that it is possible to remove metals in aqueous solution by the technique of electrocoagulation.
\end{abstract}

Keywords: Electrocoagulation, removal, heavy metals, electrolysis.

\section{Introduction}

The toxic effects of heavy metals in aqueous solution are not supposed to be demonstrated because of their carcinogenetic effect: which makes their removala necessity. There are several methods to eliminate heavy metals such as the physical and chemical methods by the addition of coagulants such as: aluminum sulfates or iron ${ }^{1}$ by the lime ${ }^{2}$, the membrane methods ${ }^{3,4}$, the adsorption on the activated carbon, the resins and the biological methods 5,6 . However, these alternatives have major inconveniences, which lie in the use of expensive of chemicals reagents and in the production of big quantities of sludge, which are toxic and difficult to store. The case of using the lime causes huge quantities of precipitate and also its substitution by the $\mathrm{NaOH}$ is not adopted because of its large toxicity and it is more expensive. The precipitation as $\mathrm{H}_{2} \mathrm{~S}$ sulfur products is very dangerous. The addition of coagulants such as the alumina sulfurs of iron allows also the production of a large amount of sludge and increases the salinity of the medium. Ion exchange treatment required working with low concentrations, and the regeneration of the ion exchange resin has a high cost. Biological treatment promotes the production of poor precipitates of soluble sulfur. Membrane methods have one obstacle; they are very expensive for a country like Morocco.These inconveniences compelled the researchers to adopt new methods that can overcome those problems. Among these methods, there is electrocoagulation which is simple, easy to operate, and it doesn't require any chemical additives and produces a few sludge ${ }^{1-16,23-42}$. The main objective of this paper is to remove heavy metals in synthetic solution by electrocoagulation (EC).

\section{Experimental and methods}

With distilled water, we prepare different heavy metal solutions at a concentration of $500 \mathrm{ppm}$ for each element $(\mathrm{Ni}, \mathrm{Cu}, \mathrm{Zn}, \mathrm{Fe}$ and $\mathrm{Pb}$ in the form of sulfate or nitrate).the dimensions of the reactor used are: diameter: $11 \mathrm{~cm}$; height: $23 \mathrm{~cm}$.

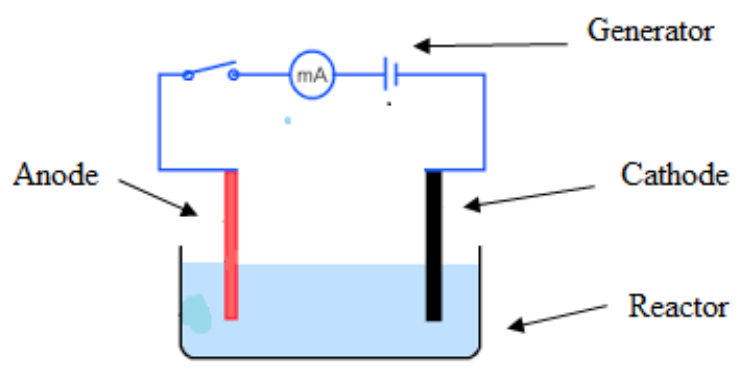

Figure 1. Electrochemical assembly 
Two identical aluminum plates of a total surface $104 \mathrm{~cm}^{2}$ distant $15 \mathrm{~mm}$ were immersed in this solution. To assure the conductivity of this solution, $2 \mathrm{~g} / 1$ of sodium chloride was added to insure the conductivity of the medium and to activate the attack of $\mathrm{Al}$ [14] the continue current is assured by a generator (0-2 A) and (0-40V) which is accompanied with a rheostat in order to vary the electric current passed in the solution. After each 15 min, a sample of this solution was taken, filtrated and then analyzed by spectroscopy of atomic absorption SAA to examine the evolution of the residual concentrations of each metal. The adjustment of the $\mathrm{pH}$ was assured by the addition of the hydroxide of sodium or the hydrochloric acid under magnetic agitation.

\section{Results and discussion}

During the passage of the electric current through the solution, liberation of the ions $\mathrm{Al}^{3+}$ caused by the oxidation of the aluminum electrode in the anode, in the cathode the formation of the hydrogen and ions hydroxides was taken place according to the following reactions ${ }^{15}$.

$$
\begin{array}{ll}
\text { Anode } & \mathrm{Al} \rightarrow \mathrm{Al}^{3+}+3 \mathrm{e}- \\
\text { Cathode } & 2 \mathrm{H}_{2} \mathrm{O}+2 \mathrm{e}^{-} \rightarrow 2 \mathrm{OH}^{-}+\mathrm{H}_{2} \\
& 2 \mathrm{H}_{2} \mathrm{O}+\mathrm{O}_{2}+4 \mathrm{e}^{-} \rightarrow 4 \mathrm{OH}^{-}
\end{array}
$$

We notice that during the electrolysis, the production of an insoluble product corresponding to metallic hydroxides has occurred. The latter were produced further due to the interactions between the ions hydroxides and the metallic ions according to the reaction:

$$
\mathrm{Al}^{3+}+\mathrm{OH}^{-} \rightarrow \mathrm{Al}(\mathrm{OH})_{3}
$$

We note that the removal of metals can be also done by reduction of the metallic ions in the cathodic areas.

Effect of the Sodium Chlorideand electric conductivity in time of treatment

\section{medium}

$\mathrm{NaCl}$ effect on the evolution of the

To assure the passage of the electric current in the solution, to increase the conductivity and to activate the dissolution of aluminium anode, a sodium chloride was added ${ }^{17,18}$.

In order to optimize the necessary quantity of the salt, we opted to study the effect of the addition of Sodium chloride on the evolution of the temperature in time of electrolysis with various concentrations of salt (Figure 2).

A Concentration of salt ranged from $1 \mathrm{~g} / \mathrm{l}$ to $3 \mathrm{~g} / \mathrm{l}$. in $\mathrm{NaCl}$ and was achieved at $25^{\circ}$. Figure 2 shows the evolution of the medium's temperature during the electrolysis; we observed that when the quantity of the salt increased in the medium, its temperature decreased. Whenthe sodium chloride's concentration wasmore than $1 \mathrm{~g} / \mathrm{l}$,

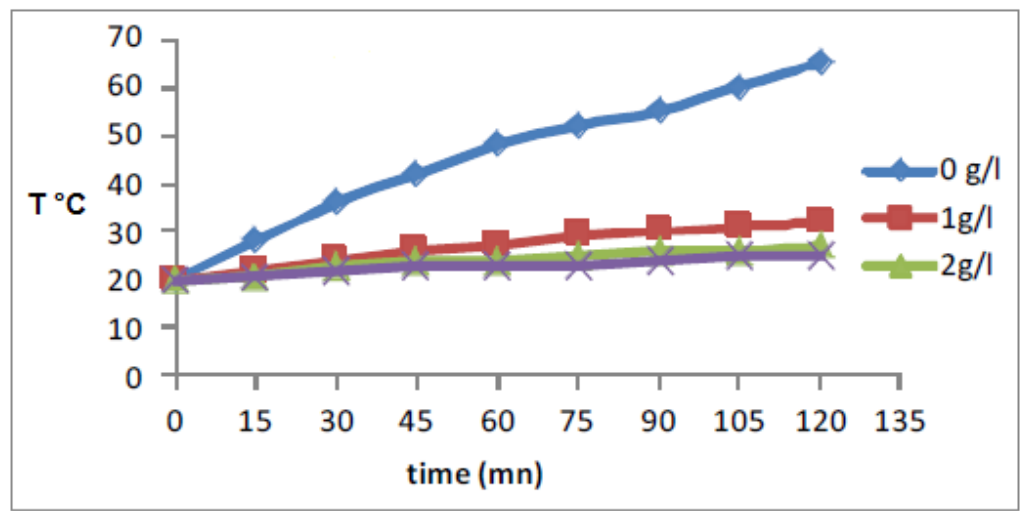

Figure 2. Effect of the addition of $\mathrm{NaCl}$ on the temperature of the solution treated

The solution's conductivity increased. Consequently, the effect of joule's phenomenon also decreased, which can be explained by the decreasing of the temperature in the presence of $\mathrm{NaCl}$.

We notice that in the absence of sodium chloride, the temperature increases in time and passes from $22^{\circ} \mathrm{C}$ to $65^{\circ} \mathrm{C}$ after two hours of electrolysis. However, in the presence of sodium chloride, the temperature varies only a little; it passes from $22^{\circ} \mathrm{C}$ to $32^{\circ} \mathrm{C}$ in 2 hours; therefore, for the consideration of other factors that influence the treatment by electrocoagulation, a concentration of $2 \mathrm{~g} / \mathrm{l} \mathrm{NaCl}$ and room temperature were retained.

\section{Evolution of the electric conductivity of the electrolyte in time of treatment}

Figure 3 shows the evolution of the conductivity of the electrolyte treated according to the time of electrolysis. We notice that there is a light increase during the first minutes of the processing; it passes from 5.3 to $5.55 \mathrm{mS} . \mathrm{cm}^{-1}$. This increase of the conductivity is explained by the addition of $\mathrm{Al}^{3+}$ ions produced by oxidation of the electrode of Aluminium in the anode:

$\mathrm{Al} \rightarrow \mathrm{Al}^{3+}+3 \mathrm{e}^{-}$ 
and of ions $\mathrm{OH}^{-}$released by the reduction of the water in the cathode: $\quad 2 \mathrm{H}_{2} \mathrm{O}+\mathrm{O}_{2}+4 \mathrm{e}^{-} \rightarrow 4 \mathrm{OH}^{-}$.

After $5 \mathrm{~min}$ of electrolysis, the conductivity decreases gradually in time to reach, after $120 \mathrm{~min}$, $2.3 \mathrm{mS}^{-\mathrm{cm}^{-1}}$. This decrease corresponds to the coagulation of $\mathrm{Al}^{3+}$ in the form of $\mathrm{Al}(\mathrm{OH})_{3}$ hydroxide and the removal of metallic ions. The electrolyte becomes poor on ions, which causes the decrease of the electric conductivity.

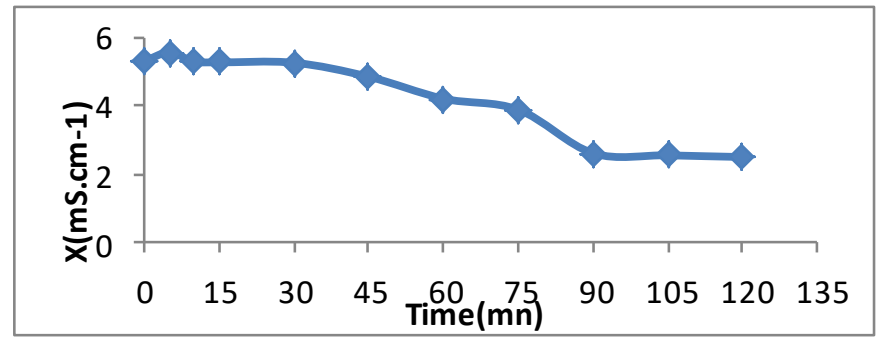

Figure 3. The evolution of the conductivity in time of treatment.

\section{Evolution of the pH in time of electrolysis}

Figure 4 shows the evolution of the $\mathrm{pH}$ during the time of electrolysis. We notice that the $\mathrm{pH}$ passes from 3.5 to 6.88 . The solution becomes practically neutral. This neutralization of the electrolyte is due to the liberation of the ions hydroxides $\mathrm{OH}^{-}$in the cathode further to the reduction of the water, which increases the $\mathrm{pH}$ according to the following reactions:

$$
\begin{aligned}
& 2 \mathrm{H}_{2} \mathrm{O}+2 \mathrm{e}-\rightarrow 2 \mathrm{OH}^{-}+\mathrm{H}_{2} \\
& 2 \mathrm{H}_{2} \mathrm{O}+\mathrm{O} 2+4 \mathrm{e}^{-} \rightarrow 4 \mathrm{OH}^{-}
\end{aligned}
$$

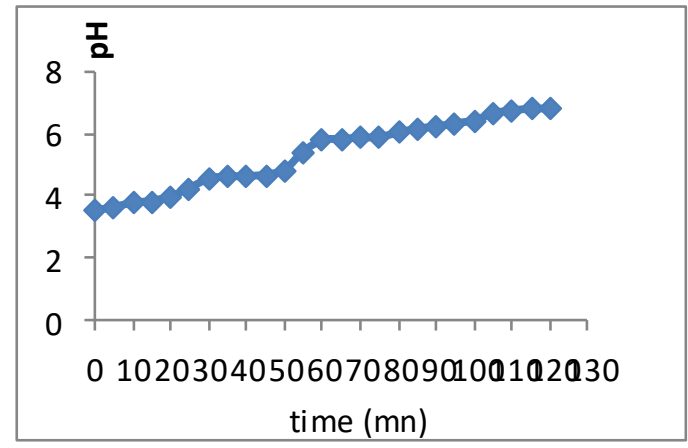

Figure 4. $\mathrm{pH}$ evolution of the medium according to time.

Figure 5, shows the evolution of the $\mathrm{pH}$ during electrocoagulation treatment of a solution containing $500 \mathrm{mg}$ of metal ions for 120 minutes and at a current density $\mathrm{I}=1 \mathrm{~A} / \mathrm{dm}^{2}$. The evolution of the final $\mathrm{pH}$ depending on the initial $\mathrm{pH}$ : after each treatment, the final $\mathrm{pH}$ of the medium increases; this can be explained by the generation of $\mathrm{OH}^{-}$ions on the cathode and the substitution of $\mathrm{OH}^{-}$ions by the chloride ions in the aluminum.

\section{Effect of the time of electrolysis}

The liquids discharges are usually acid, neutral or basic. So, we proceeded to study the kinetics of the removal of metals by EC with various values of $\mathrm{pH}(4,7$ and 10). According to the Figures 6, 7 and 8
We also notice that the evolution of the $\mathrm{pH}$ is made according to two stages:

1/ During the first 50 minutes, where the $\mathrm{pH}$ increases quickly and passes from 3.5 to 4.75 . The hydroxides ions still not taking place.

2/ After the 50 min of electrolysis where a jump of $\mathrm{pH}$ was observed from 4.75 to 5.8 (during ten minutes). Between 60 and 120 minutes of electrolysis the increase of the $\mathrm{pH}$ is slowed down and reaches a value of 6.88 at the end of the treatment ${ }^{17}$.

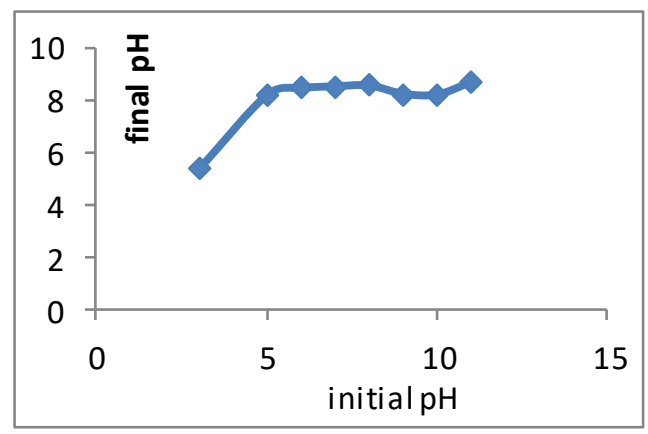

Figure 5. Evolution of the final $\mathrm{pH}$ depending on the initial $\mathrm{pH}$.

which present the residual concentrations of existing metals in terms of the time of electrolysis in various $\mathrm{pH}$ initial of medium. The concentration of the various metallic ions decreases in all cases in time of the electrolysis.

We noted also that the initial concentrations of the metallic ions depend on the medium $\mathrm{pH}$, due to their stabilities ${ }^{10}$. In $\mathrm{pH}=4$, the ions $\mathrm{Pb}^{2+}, \mathrm{Cu}^{2+}$ and $\mathrm{Ni}^{2+}$ have almost the same speed of precipitation and were practically eliminated after 45 minutes of treatment (Figure 6). However, for $\mathrm{Zn}^{2+}$ and $\mathrm{Fe}^{2+}$ $\left(\right.$ or $\mathrm{Fe}^{3+}$ ) ions, they were eliminated only after 105 min. So we can conclude that there is a selectivity of metals during the treatment. 


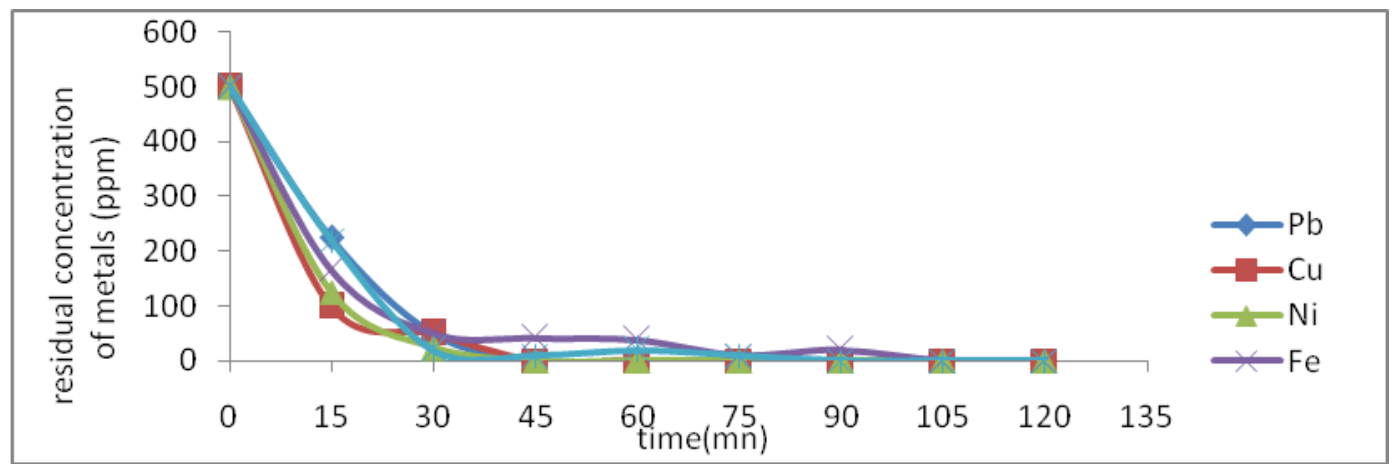

Figure 6. Treatment by electro coagulation of a metallic's solution: $(\mathrm{Cu}, \mathrm{Zn}, \mathrm{Fe}, \mathrm{Pb}$ et $\mathrm{Ni})$ at $\mathrm{pH}$ initial $=4$

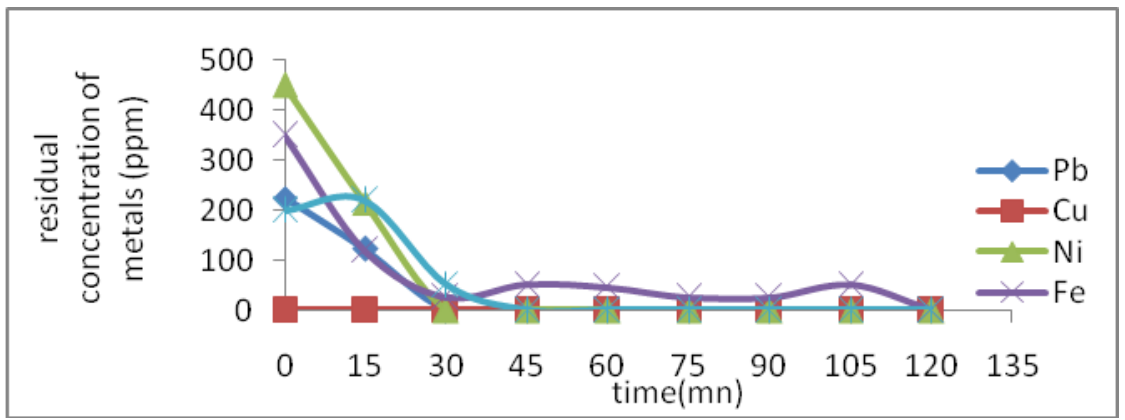

Figure 7. Treatment by par electrocoagulation of a metallic's solution: $(\mathrm{Cu}, \mathrm{Zn}, \mathrm{Fe}, \mathrm{Pb}$ and $\mathrm{Ni})$ at $\mathrm{pH}$ initial $=7$

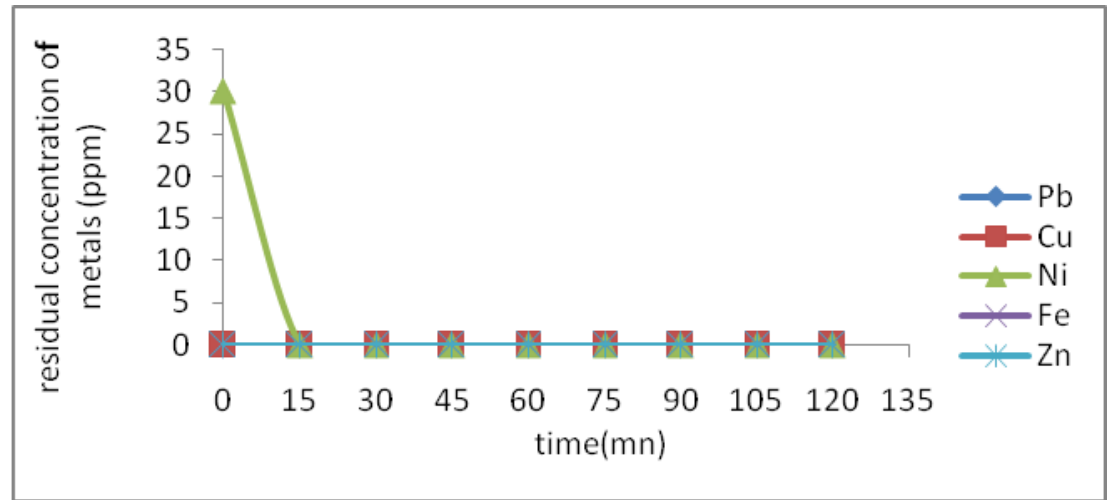

Figure 8. Treatment by par electro coagulation of a metallic's solution: $(\mathrm{Cu}, \mathrm{Zn}, \mathrm{Fe}, \mathrm{Pb}$ and $\mathrm{Ni})$ at $\mathrm{pH}$ initial $=10$

In $\mathrm{pH}=7$, only the copper precipitates totally and immediately, the other elements precipitate only partially at the beginning of the processing. However, only the nickel remains insensible to the variation of the $\mathrm{pH}$ (Figure 7). The phenomenon of precipitation of the metallic ions with the $\mathrm{pH}$ depend on their stability and to the affinity of the reaction of every element with the ions hydroxides. So, the copper reacts immediately with the ions $\mathrm{OH}^{-}$to neutral or basic $\mathrm{pH}$, given its big affinity with these ions ${ }^{19}$.

In neutral $\mathrm{pH}$, the optimal precipitation's time of $\mathrm{Cu}$ is about $10 \mathrm{~min}$, while for the $\mathrm{Pb}$ and $\mathrm{Ni}$ it is about $15 \mathrm{~min}$ and it is much slower for $\mathrm{Zn}$ (45 min) and for Fe (120 min).

We also notice for $\mathrm{Zn}$ and $\mathrm{Fe}$, in the acid and neutral medium (Figures 5 and 6), that there is a fluctuation in their residual concentrations during the treatment. This fluctuation can be explained by the phenomenon of coagulation-dissolution. As for the (Figure 8), it shows that in the basic medium the optimal duration of precipitation is relatively much shorter than in acid medium, because of the strong concentration of the electrolyte in ions $\mathrm{OH}-$. The ions $\mathrm{Cu}^{2+}, \mathrm{Pb}^{2+}, \mathrm{Zn}^{2+}$ and $\mathrm{Ni}^{2+}$ have a big affinity of reaction with the $\mathrm{OH}^{-}$ions to form metallic hydroxides which are generally very stable ${ }^{20-21}$.

However, we notice that in $\mathrm{pH}=10$ all the metallic ions study precipitates immediately except the Nickel which is eliminated from the solution after 15 minutes of electrolysis.

We notice that there are several competitive reactions near of the cathode: the reduction of ionic metals, precipitation and a co-precipitation of metals 
under hydroxides forms. As the results show, there is firstly a reduction of metals on the cathode which dominates because of their high concentrations, and secondly, we notice that this reduction grows in the following order: $\mathrm{Cu}>\mathrm{Pb}>\mathrm{Ni}>\mathrm{Zn}$ according to their normal potential $\left(\mathrm{E}^{\circ} \mathrm{Zn}^{2+} / \mathrm{Zn}=-0,76 \mathrm{~V}<\mathrm{E}^{\circ} \mathrm{N}^{2+} / \mathrm{Ni}=\right.$ $\left.-0,25 \mathrm{~V}<\mathrm{E}^{\circ} \mathrm{Pb}^{2+} / \mathrm{Pb}=-0,13 \mathrm{~V}<\mathrm{E}^{\circ} \mathrm{Cu}^{2+} / \mathrm{Cu}=0,345 \mathrm{~V}\right)$ and their corresponding solubility and their formation energies of their equivalent hydroxides 22,25 .

\section{Effect of current density}

To study the effect of current density applied during the electrolysis, we followed the residual concentration of the various metallic ions studied according to the density of the current applied, during electrolysis time of $120 \mathrm{~min}$ and a concentration of $500 \mathrm{ppm}$ for each of the ions (Figure 9). We notice that the rate of removal of metals increases with the density of the current. Indeed, when we apply current densities between 0,1 and $0,5 \mathrm{~A} / \mathrm{dm}^{2}$, the maximal rate of removal of metals does not exceed $64,5 \%$. However, it exceeds
$90 \%$ for current density higher than $1 \mathrm{~A} / \mathrm{dm}^{2}$ and reaches a maximum of $99.9 \%$ for a current density of $1.5 \mathrm{~A} / \mathrm{dm}^{2}$. This result could be explained by the important liberation of the ions $\mathrm{OH}^{-}$and the reduction of metallic ions responsible for the removal of studied metals. Indeed, this phenomenon depends strongly on the strength of current applied to electrodes according to the Faraday's law:

\section{m $=$ I. t. $M / z$. F}

where I is the strength of current applied, $t$ : the time of the electrolysis, M: the molar mass of the element, $\mathrm{z}$ : the number of electrons and F: the number of Faraday $\left(96486 \mathrm{C} . \mathrm{mol}^{-1}\right)$. There is also a strong gaseous release $\left(\mathrm{H}_{2}\right)$ on the cathode further to the reduction of the water:

$2 \mathrm{H}_{2} \mathrm{O}+2 \mathrm{e}^{-} \rightarrow 2 \mathrm{OH}^{-}+\mathrm{H}_{2}$.

The gaseous released facilitates the separation of the solid phase (precipitate metallic) of the electrolyte ${ }^{21,22}$.

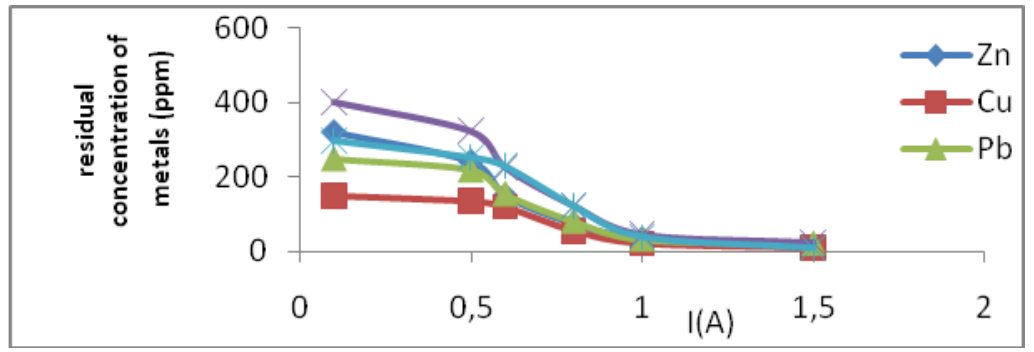

Figure 9. Removal of metals according to the current intensity $(\mathrm{t}=120 \mathrm{~min}$, initial concentration 500ppm, $\mathrm{pH}=5)$

\section{Effect of the initial pH}

Figure 10 shows the effect of the initial $\mathrm{pH}$ on the treatment processes of the ions studied in a solution containing $500 \mathrm{ppm}$ of every metal, the initial $\mathrm{pH}$ was chosenfrom2 to 12 , current density: 1 $\mathrm{A} / \mathrm{dm}^{2}$ during $120 \mathrm{~min}$.

We notice that the rate of removal of these various metals is from 90 to $95 \%$ for $\mathrm{pH}$ between 4 and 6 and reach a maximum when $\mathrm{pH}$ is superior to 6 . However, in $\mathrm{pH}<4$, this rate is very low and it is only approximately about $55 \%$ in $\mathrm{pH}=2$. These low efficiencies can be explained by re-dissolution of precipitates (metallic hydroxides) in acid medium ( $\mathrm{pH}$ lower than 4). However, higher efficiencies were reached in neutral or basic mediums thanks to the higher stability of the precipitate.

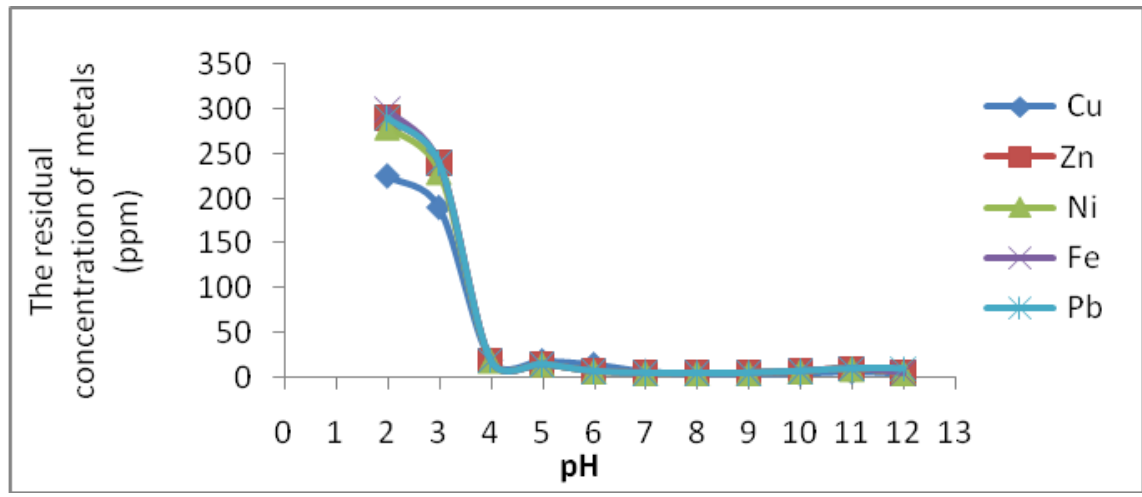

Figure 10. Effect of the initial $\mathrm{pH}$ on the removal of metallic's ions 


\section{Effect of initial concentration of the removed metal}

In order to observe the effect of the initial concentration on the speed of removal of this metal, solutions of various concentrations of $\mathrm{Cu}(500,250$, 200, 100 and $50 \mathrm{mg} / \mathrm{l}$ ) were prepared.

The obtained results (Figure 11) show that the speed of removal of $\mathrm{Cu}$ increases when its initial concentration decreases. The same behaviour is observed for the other metals ( $\mathrm{Zn}, \mathrm{Pb}, \mathrm{Fe}$ and $\mathrm{Ni}$ ). The effect of the concentration is explained by the fast adsorption of these metals on the cathode or on aluminium polymeric hydroxides and also by the high collision probability of entities in the diluted solutions. It can be suggested that EC is very effective for dilute concentration.

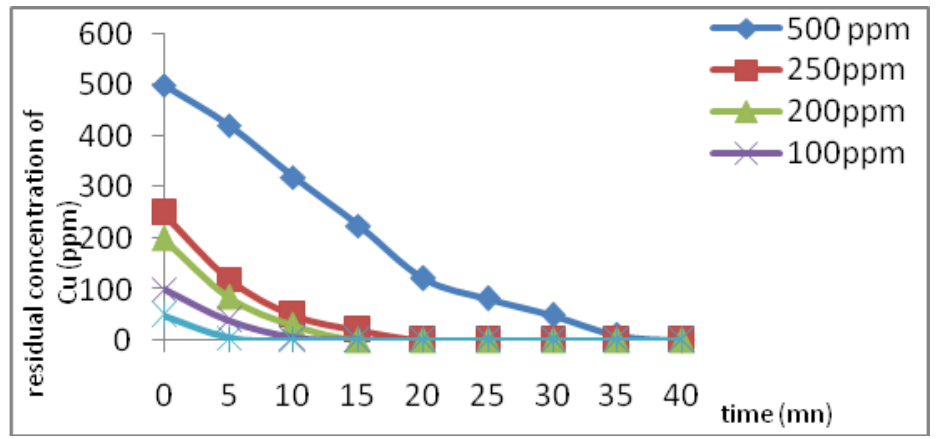

Figure 11. Removal of $\mathrm{Cu}$ according to the initial concentration with $(\mathrm{I}=1 \mathrm{~A}, \mathrm{pH}=6)$

\section{Conclusion}

This study shows that it is possible to remove heavy metals in synthetic wastewater $(\mathrm{Ni}, \mathrm{Pb}, \mathrm{Cu}, \mathrm{Fe}$ and $\mathrm{Zn}$ ) by the technique of Electrocoagulation. The rate of removal can reach $99.9 \%$. The parameters which act on the efficiency of this electrochemical method were: the time of electrolysis, the conductivity, the initial $\mathrm{pH}$, the initial metallic concentration and the density of the current. In our case, the optimal conditions of treatment were: an initial $\mathrm{pH}$ between 6 and 8 , the density of the current ranged from 1 to $1,5 \mathrm{~A} / \mathrm{dm}^{2}$, and duration of electrolysis is dependent on the metallic ion to be treated. We noted that there is selectivity during the removal of metals, governed by their standard potentials and the energies of formation of hydroxides. So the order of the selectivity is as follow: $\mathrm{Cu}>\mathrm{Pb}>\mathrm{Ni}>\mathrm{Zn}>\mathrm{Fe}$.

\section{References:}

1- R.C. Chenh, J.Am.Water Works Assoc., 1994, 86.79 .

2- L.Hartinger ,Handbuch der Abwasser- und Rcyclingtechnik,CarlHanserVerlag, MunchenWien,(1991).

3- D.J. Chang and S.T. Hwang, Sep. Sci.Technol., 1996, 31, 1831 .

4- D. Green and J. Menller, Method for removing sulfates and metal ions from waters and waste waters, PCT Int . Appl.WO $0000273(\mathbf{2 0 0 0})$.

5- E. Wilkins, Q. Yang, J. Env. Sci. Health, 1996, A31, 2111.

6- G. Bereket, A. Aroguz, M. Özel, J. Colloid. Appl. Sci., 1997, 187,338.

7- A. Brady, Environ .Technol., 1994, 15, 429.

8- B. W. Atkison, F. Bux, L. Kasen, Water Sci. Technol., (G.B), 1996, 34, 9.
9- W. Phutdhawong, S. Chowwanapoonpohn, D. Buddhasukh, Electrocoagulation and subsequent Recovery of Phenolic compounds, Anal. sci., 2000, Vol. 16, 1083.

10- D. Harvey, Modern Analytical Chemistry Boston Burr Ridge: McGraw-Hill Companies,Inc.,(2000).

11- M.Y.A. Mollah, R. Schennach, J.R. Parga, D.L. Cocke, Electrocoagulation science and applications, J. Hazard. Mat., 2001, Vol. 84, 29-41.

12- N.V. Sidgwick, The chemical elements and their compounds, London, Oxford University Press(1962)

13- X. Chen, G.Chen, P.L Yue, Separation of pollutants from restaurant wastewater by electroagualtion, Sep Technol., 2000, 19, 65-76.

14- T. Picard, G. Gathalifaud-Feuillade, M. Mazet, C. Vandensteendam, Cathodic dissolution in the electrocoagulation process using aluminium electrodes, J. Environ. Monit., 2000, 2, 77-80.

15- P. Canizares, F. Martinez, C. Jimenez, J. Lobato, M.A. Rodrigo, Comparison of the $\mathrm{Al}$ speciation in chemical and electrochemical processes, Ind. Eng. Chem. Res., 2006, 45, 8749-8750.

16- B. Merzouka,, B. Gourich, A. Sekki, and col. Removal turbidity and separation of heavy metals using electrocoagulation-electroflotation technique A case study. J. Hazard. Mat., 2009, vol. 164, 215-222.

17- C. H. Huang, L. Chen, C. L. Yang, Effect of anions on electrochemical coagulation for cadmium removal, Sep. Purif. Technol., 2009, 65, 137-146

18- Ö. Hanay, H. Hasar, Effect of anions on removing $\mathrm{Cu}^{2+}, \mathrm{Mn}^{2+}$ and $\mathrm{Zn}^{2+}$ in electro- 
coagulation process using aluminum electrodes, J. Hazard Mat., 2011, 189 572-576.

19- E. Bazrafshan, Performance evaluation of electrocoagulation process for removal of chromium (VI) from synthetic chromium solutions using iron and $\mathrm{Al}$ electrodes, Turk. J. Eng. Environ. Sci., 2008, 32, 59-66.

20- M.S. Bhatti, A.S. Reddy, A.K. Thukral, Electrocoagulation removal of $\mathrm{Cr}$ (VI) from simulated wastewater using response surface methodology, J. Hazard. Mater., 2009, 172, 839-846

21- O.T. Can, M. Bayramoglu, The effect of process conditions on the treatment of benzoquinone solution by electrocoagulation,J. Hazard. Mater., 173 (2010), pp. 731-736.

22- F. Akbal, S. Camc, Comparison of electrocoagulation and chemical coagulation for heavy metal removal, Chem. Eng. Technol., 2010, 33(10), 1655-1664.

23- M. Behbahani, M.R. Alavi Moghaddam, M. Arami, Fluoride removal by electrocoagulation process: optimization through response surface methodology Desalination, 2011, 271, 209-218.

24- A.H. El-Shazly, A.A. Al-Zahrani, S.S. AlShahrani, Improvement of $\mathrm{NO}_{3}{ }^{-}$removal from wastewater by using electrocoagulation unit with vertical monopolar Al electrodes, Int. J. Electrochem. Sci., 2011, 6, 4141-4149.

25- K. Dermentzis, A. Christoforidis, E. Valsamidou, Removal of $\mathrm{Ni}, \mathrm{Cu}, \mathrm{Zn}$ and $\mathrm{Cr}$ from synthetic and industrial wastewater by electro coagulation, J. Environ. Sci., 2011,1, 697- 710.

26- S. Bellebia, S. Kacha, A. Z. Bouyakoub, Z. Derriche, Experimental investigation of chemical oxygen demand and turbidity removal from cardboard paper mill effluents using electro coagulation and adsorption processes, Environ. Prog. Sustain. Energy, 2012, 31(3), 361-370.

27- E-S. Z. El-Ashtoukhy, Y.A. El-Taweel, O. Abdelwahab2, E.M.Nassef, Treatment of petrochemical waste water containing phenolic compounds by electro coagulation, Int. J. Electrochem. Sci., 2013, 8, 1534-1550.

28- A. R. Amani-Ghadima, S. Abera, and col. Optimization of electrocoagulation process for removal of an azo dye using response surface methodology, Chem. Eng. Process., 2013, 64, 68-78.

29- A.K. Chopra, A.K. Sharma, Removal of turbidity, COD and BOD from secondarily treated sewage water by electrolytic treatment, Appl. Water Sci., 2013, 3, 125-132.

30- Y.T. Chung, L.N. Ng, A.W. Mohammad, Sulfonated-polysulfone membrane surface modifica- tion by employing methacrylic acid through UV-grafting, J. Ind. Eng. Chem., 2014, 20,1549-1557.
31- I. Elksibi, W. Haddar, M.B. Ticha, R. Gharbi, M. Mhenni, Development and optimisation of a non conventional extraction process of natural dye from olive solid waste using response surface methodology, Food Chem., 2014, 161, 345-352.

32- A. Fakhri, Investigation of $\mathrm{Hg}$ (II) adsorption from aqueous solution onto copper oxide nano particles: optimization using response surface methodology, Process Saf. Environ., 2015, 93, 1-8. DOI: 10.1016/j.psep.2014.06.003.

33- S. Vasudevan, M.A. Oturan, Electrochemistry as Cause and Cure in Water Pollution. An Overwiew. Environmental Chemistry Letters, Springer Verlag, 2013, DOI: 10.1007/s10311013-0434-2.

35- G. Sozhan, S. Mohan, S. Vasudevan, $\underline{\text { R. }}$ Balaji, S. Pushpavanam. Recovery of Chromium from the Solid Residue by In-SituGenerated Hypochlorite. Ind. Eng. Chem. Res., 2006, 45 (23), pp 7743-7747.

36- R. Kamaraj, S.Vasudevan. Evaluation of electrocoagulation process for the removal of strontium and cesium from aqueous solution Chemical Engineering Research and Design, 2015, 93, 522-530.

37- S. Vasudevan, J. Lakshmi, G. Sozhan. Studies on the Al-Zn-In-alloy as anode material for the removal of chromium from drinking water in electrocoagulation process. Desalination, 2011, 275, 260-268.

38- J. Lakshmi, S. Vasudevan. Graphene a promising material for removal of perchlorate $\left(\mathrm{ClO}_{4}{ }^{-}\right)$from water. Environmental Science and Pollution Research, 2013, 20, 5114-5124.

39- S. Vasudevan, G. Sozhan, S. Mohan, R. Balaji, P. Malathy. Electrochemical Regeneration of Chromium Containing Solution from Metal Finishing Industry. Ind. Eng. Chem. Res., 2007, 46, 2898-290.

40- S.Vasudevan, J. Lakshmi, R. Vanathi, Electrochemical Coagulation for Chromium Removal: Process Optimization, Kinetics, Isotherms and Sludge Characterization CleanSoil, Air, 2010, 38, 9-16.

41- S. Vasudevan, J. Lakshmi, Studies relating to an electrochemically assisted coagulation for the removal of chromium from water using zinc anode. Water Science and Technology: Water supply, 2011, 11 (2), 142150; DOI: 10.2166/ws.2011.032.

42- P. Ganesan, R. Kamaraj, S.Vasudevan. Application of isotherm, kinetic and thermodynamic models for the adsorption of nitrate ions on graphene from aqueous solution. Journal of the Taiwan Institute of Chemical Engineers, 2013, 44, 808-814. 